\title{
Erratum
}

\section{Trends in the Management of Type 2 Diabetes and its Prescription Drug Costs in Greece (1998 \& 2006)}

S. Liatis, P. Thomakos, S. Papaoikonomou, A. Papazafeiropoulou, N. Giannakopoulos, E. Karagiaouri, A. Sotiropoulos, S. Bousboulas, A. Melidonis, S. Pappas, N. Katsilambros

Exp Clin Endocrinol Diabetes 2009; 117 (9): 505-510

One of the author's name is misspelt. The correct name is Athanasia Papazafiropoulou. 